\title{
EFFECT ON MACULAR EDEMA IN NON-ISCHEMIC CRVO: COMPARISON BETWEEN INTRAVITREAL BEVACIZUMAB AND COMBINED INTRAVITREAL BEVACIZUMAB AND TRIAMCINOLONE
}

Murali Mohan Gurram.

1. Associate Professor, Department of Ophthalmology, Kamineni Academy of Medical Sciences.

\section{CORRESPONDING AUTHOR:}

Dr. Murali Mohan Gurram

Department of Ophthalmology

Kamineni Hospitals. L.B.Nagar

Hyderabad-500068

E-mail: drmmgi@gmail.com

PURPOSE: to compare the efficacy of intravitreal bevacizumab and combined bevacizumab and Triamcinolone, in the treatment of macular edema in CRVO. The efficacy is studied by the anatomical and visual improvements. BACKGROUND: macular edema is the most common cause of visual loss in central retinal vein occlusion. Many treatments have been advocated with the recent trend being the usage of intravitreal anti-VEGF agents and steroids. METHODS: 30 eyes of 30 patients (17 male and 13 female) with recent onset non-ischemic CRVO were enrolled in a prospective randomized consecutive comparative study. Group I with 15 eyes were given intravitreal injection of $1.25 \mathrm{mg} / 0.05 \mathrm{ml}$ of Avastin and group II with 15 eyes were given intravitreal combination of $1.25 \mathrm{mg} / 0.05 \mathrm{ml}$ Avastin and $2 \mathrm{mg} / 0.05 \mathrm{ml}$ of Triamcinolone. All eyes were examined at baseline and at six weeks of injection. Changes in best corrected visual acuity (letters of ETDRS chart) and central macular thickness were studied. IOP was also focused on. RESULTS: In group I the BCVA increased from 34.80 \pm 7.01 letters to $49.3 \pm 5.82$ letters with an increase of $14.33 \pm 7.40$ letters $(\mathrm{P}=0.0001)$. The Mean CMT in group I changed from $578.27 \pm$ $115.36 \mu$ to $204.00 \pm 13.57 \mu$ with a decrease of $374.27 \pm 107.74 \mu(\mathrm{P}=0.0001)$. In group II BCVA increased from $30.07 \pm 9.38$ letters to $47.73 \pm 11.59$ letters by $17.67 \pm 13.60$ letters $(\mathrm{P}=0.001)$ and mean CMT decreased from $586.27 \pm 144.94 \mu$ to $209.40 \pm 18.38 \mu$ with a change of $376.87 \pm 153.32 \mu$ $(\mathrm{P}=0.004)$. There was no significant difference between these two groups with regards to mean BCVA ( $\mathrm{P}=0.411)$ and CMT $(\mathrm{P}=0.958)$.

Three eyes in group I had subconjunctival hemorrhage. In group II two patients had subconjunctival hemorrhage and two patients had rise in IOP which was controlled medically.

CONCLUSIONS: Intravitreal injection of bevacizumab alone or combined bevacizumab + triamcinolone had a beneficial effect on visual acuity improvement and central macular thickness reduction, in macular edema associated with central retinal vein occlusion. Our results showed that both are equally efficacious. Multicentre randomized trials with longer followup are needed to evaluate the long term safety and efficacy of this combination treatment.

INTRODUCTION: Central retinal vein occlusion (CRVO) is one of the most common retinal causes for diminished vision. An Indian study showed a prevalence of $0.1 \% .{ }^{1}$ It's common in older age group. The pathologic site is the block behind lamina cribrosa. There are two variants, non ischemic 
and ischemic. ${ }^{2}$ The causes for visual loss are macular edema and ischemia. Macular edema(ME) is the most common cause for visual loss in both variants of CRVO.

Venous occlusion leads to poor venous drainage, dilatation and tortuosity of the large retinal veins, and increased retinal capillary pressure. These changes lead to secondary inflammation and result ultimately in breakdown of blood retinal barrier with, exudation of blood, fluid, and lipid into the retina, leading to the development of macular edema. ${ }^{3}$

Role of Vascular Endothelial Growth Factor (VEGF) has been established. The increased backpressure leads to stagnation of blood flow, which leads to hypoxia of retina. This causes release of various chemical agents, of which VEGF is important. ${ }^{4} 5$ VEGF is the major vasopermeability factor that disrupts the blood-retina barrier in Retinal vein occlusion(RVO) by inducing fenestrations in capillaries and venules. ${ }^{6}$

Treatment of ME is very important to improve the vision of the patient. In a study, no case of macular edema with central retinal vein occlusion resolved spontaneously by 1 year, but approximately 30\% resolved spontaneously over a long interval, often with neuro retinal or pigment epithelial scarring and atrophy. ${ }^{7}$ when resolution of ME does occur, it can be long delayed. In one study, the time to resolution of ME in untreated nonischemic CRVO with ME averaged 23 months compared to 29 months for ischemic CRVO. ${ }^{8}$

Macular grid laser was considered the gold standard treatment. The photocoagulation of the photoreceptors reduces the oxygen consumption of the outer retina and allows oxygen to diffuse from the choroid to the inner retina, where it relieves hypoxia.9, 10 But Central Vein Occlusion Study (CVOS) proved that the macular grid laser is not useful in improving the vision. There was no statistically significant difference between treatment and control visual acuity at any stage of follow-up. 11

Laser induced chorioretinal anastomosis has been proposed with some reports of good results. It helps by creating a bypass from central retinal vein to choroidal circulation. ${ }^{12}$ But it is not widely used due to the complications involved.$^{13}$

Triamcinolone acetonide is a corticosteroid that, in addition to its anti-inflammatory effects, may cause down-regulation of vascular endothelial growth factor (VEGF). ${ }^{14}$ Triamcinolone intravitreally was largely used with good results.15,16,17,18Triamcinolone may be associated with complications like glaucoma, cataract etc. ${ }^{19}$

SCORE study 5 (Standard Care VS Corticosteroid for Retinal Vein Occlusion (SCORE) study report 5)has concluded that the Intravitreal triamcinolone (IVT) is superior to observation for treating vision loss associated with ME secondary to CRVO. It also showed that lower dose of triamcinolone $\left(1 \mathrm{mg}\right.$ ) is as effective as $4 \mathrm{mg}$ with less side effects. ${ }^{21}$

Bevacizumab (Avastin, Genentech Inc., San Francisco, CA) is a full length humanized monoclonal antibody against all Isoform of VEGF-A and binds to the VEGF molecule to prevent receptor binding. It has the USFDA approval for intravenous treatment for metastatic colon cancer. Off-label use of it intravitreally, is in vogue since few years. Since the first report of the efficacy of intravitreal bevacizumab (IVB) in a patient with ME secondary to CRVO in 2005,21 several case series have shown the benefit of this treatment, with an improvement in visual acuity and a decrease of Central Macular Thickness(CMT) in patients with ME with CRVO. ${ }^{22,23}$

Intravitreal bevacizumab and triamcinolone were equal in visual improvement and reduction in macular thickness as shown by many studies. But the complication rate was high in triamcinolone 
group. ${ }^{24,} 25$ Equally good results were obtained with combined Avastin and triamcinolone. ${ }^{26}$ Combining both triamcinolone and bevacizumab in the intravitreal injection, will it have any added advantage, when compared to bevacizumab alone? There is no study, which compared these two. This study is to compare the efficacy of IVB with that of combined Bevacizumab and Triamcinolone in ME associated with Non-ischemic CRVO.

MATERIALS AND METHODS: Prospective randomized comparative study. Setting is a tertiary eye care in Hyderabad, south India.

March 2011 to march 2013

Ethics committee approval has been taken prior to the study. Patients were explained about the study, the drug and its off-label usage, and the consent taken.

\section{INCLUSION CRITERIA:}

1. Macular edema with Non-Ischemic Central Retinal Vein Occlusion as evidenced by clinical and angiographic evaluation

2. Decreased vision with vision better than PL.

3. $\mathrm{CMT} \geq 250 \mu$

\section{EXCLUSION CRITERIA:}

1. Ischemic CRVO

2. Prior laser treatment

3. Glaucoma/Ocular Hypertension

4. Cataract which precludes the evaluation of macula

5. Vitreous hemorrhage

6. Ischemic heart disease

7. Renal insufficiency

8. Macular ischemia

9. Iris neovascularization

10. Prior intravitreal injections

Total number of 30 eyes of 30 patients was included after taking written informed consent. All these patients underwent basic eye examination including Best corrected visual acuity with 4 meter ETDRS chart (4m ETDRS chart model no. 2121, Akriti Logistics), thorough slit lamp examination, Goldman Applanation Tonometry, Contact lens biomicroscopy, Indirect ophthalmoscopy, FFA, and OCT (Time domain OCT, Zeiss Stratus OCT). These were randomized to two groups. Group I was given intravitreal bevacizumab $(1.25 \mathrm{mg} / 0.05 \mathrm{ml}$. Group II was given combination of bevacizumab $1.25 \mathrm{mg}$ and $2 \mathrm{mg}$ Triamcinolone Acetonide. The following table illustrates the baseline data of patients.

Table 1. Demographics of the patients 


\begin{tabular}{|l|l|l|l|}
\hline & $\begin{array}{l}\text { GROUP (Avastin) } \\
\text { Mean } \pm \text { SD } \\
\text { N=15 }\end{array}$ & $\begin{array}{l}\text { GR0UP II (Avastin + } \\
\text { Triamcinolone) } \\
\text { Mean } \text { I SD } \\
\text { N=15 }\end{array}$ & P value \\
\hline Age & $58.13 \pm 9.81$ & $61.8 \pm 11.97$ & 0.367 \\
\hline Male & $8(53 \%)$ & $9(60 \%)$ & \\
\hline Female of & $7(47 \%)$ & $6(40 \%)$ & 0.974 \\
\hline $\begin{array}{l}\text { Duration Acuity } \\
\text { symptoms (days) }\end{array}$ & $34.80 \pm 7.01$ & $8.4 \pm 5.5$ & 0.129 \\
\hline $\begin{array}{l}\text { Visual letters } \\
\text { (number of } \\
\text { ETDRS chart) }\end{array}$ & $30.07 \pm 9.38$ & 0.868 \\
\hline $\begin{array}{l}\text { Central Macular } \\
\text { Thickness (Microns) }\end{array}$ & $578.27 \pm 115.36$ & $586.27 \pm 144.95$ & \\
\hline
\end{tabular}

The technique of injection: All injections were given in sterile environment of operation theatre. Povidone iodine drops were instilled in the eye prior to painting and draping. After placement of eye speculum, measurement is taken which are $3.5 \mathrm{~mm}$ for pseudophakic and aphakic and $4 \mathrm{~mm}$ for phakic eyes. Inferotemporal quadrant is selected. Conjunctiva is displaced and injection is given in a tunneled incision technique. ${ }^{27} 1.25 \mathrm{mg}$ of Avastin in $0.05 \mathrm{ml}$ is used from a multi dose vial. (Avastin; Genetech Inc., California, USA).

For group II, initially the tuberculin syringe is loaded with $0.05 \mathrm{ml}$ of Avastin, later $2 \mathrm{mg}(0.05 \mathrm{ml})$ of the preservative free triamcinolone acetonide (Aurocort, Aurolabs, India) is loaded into the syringe. Needle is exchanged with a new 26G needle for the injection. The technique remains the same.

Post operative instructions for all patients were same with oral antibiotic, acetazolamide and NSAID. Topical medications include Steroid-Antibiotic combination for five days. Acetazolamide $250 \mathrm{mg}$ is given thrice daily for one day. Antibiotic for 5 days and NSAID is given for 2 days.

Patients are seen one day later for any complications like endophthalmitis, vitreous hemorrhage, secondary glaucoma etc.

Second evaluation was after a six weeks of injection. They are examined with the same parameters like VA, GAT, IO, FFA, OCT etc.

OBSERVATIONS: On $1^{\text {st }}$ post op day, 3 patients in group 1 showed Subconjunctival hemorrhage at the site of injection, and the rest showed no problems. In group II 2 patients had subconjunctival hemorrhage, and two patients had raised IOP which was controlled with medications. None of the patients had severe problems like, endophthalmitis, vitreous hemorrhage or retinal lesions.

All the patients turned up for six weeks followup. All the patients in both groups showed symptomatic improvement. All of them showed improvement of atleast one number in ETDRS 
BCVA, and reduced macular thickness. None of them had any major complications. Only one patient in group 2 had raised IOP, which got controlled with Topical Brimonidine.

The pre-op and post-op measurements are charted below:

Chart 1: Change in Mean visual acuity

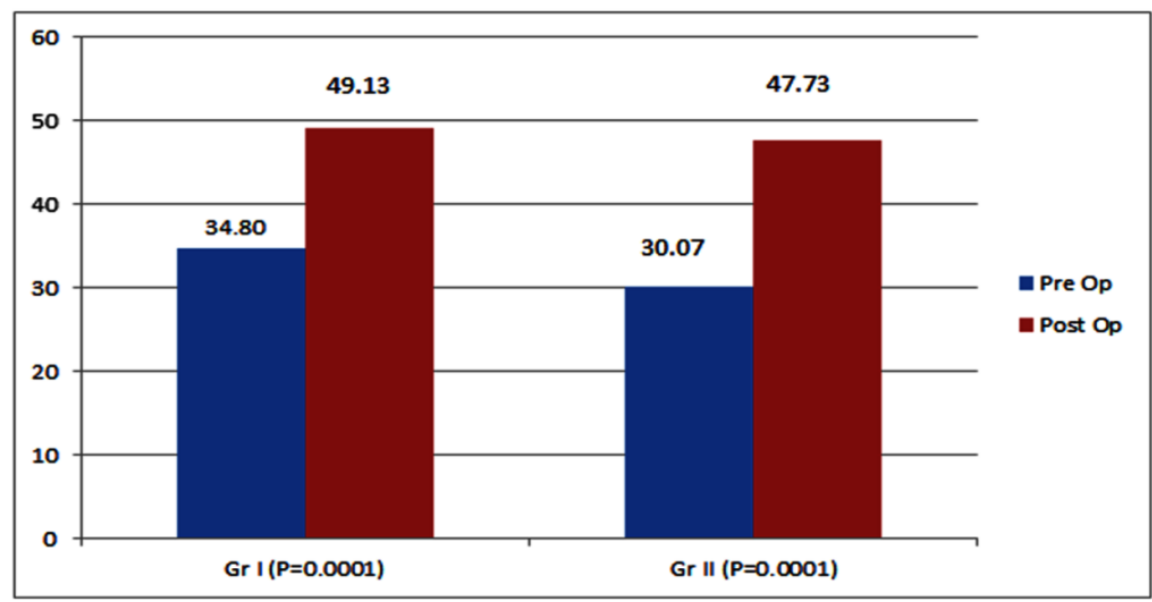

In group I the preop Visual acuity was $34.80 \pm 7.01$ (Mean \pm Standard deviation) which improved to $49.3 \pm 5.82$. There was increase in the BCVA by $14.33 \pm 7.40$.

Visual acuity in group II increased from $30.07 \pm 9.38$ to $47.73 \pm 11.59$ by $17.67 \pm 13.60$.

The Central Macular thickness in group I changed from $578.27 \pm 115.36$ to $204.00 \pm 13.57$ with a decrease of $374.27 \pm 107.74$.

Central macular thickness in group II decreased from pro op value of $586.27 \pm 144.94$ to post op value of $209.40 \pm 18.38$ the change was $376.87 \pm 153.32$.

Chart 2: Change in Mean CMT

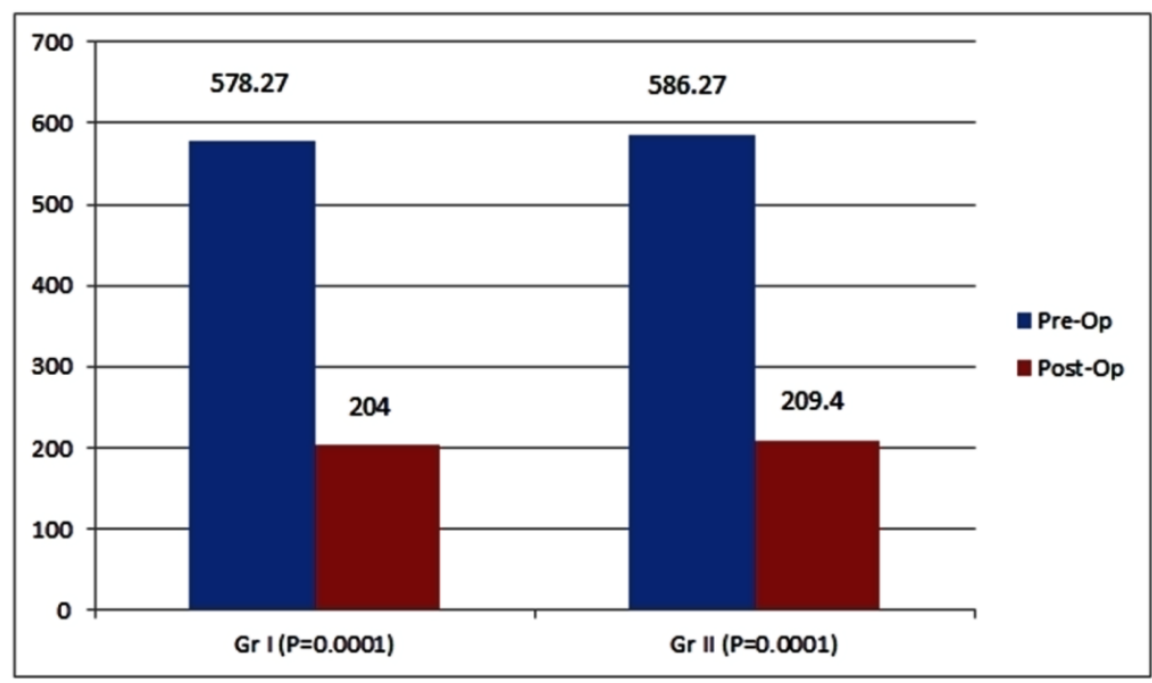


STATISTICAL ANALYSIS: Statistical Analysis was made with SPSS software (SPSS for Windows, version 13.0, SPSS Inc., Chicago, Illinois, USA). For the effect on BCVA and CMT in each group, Paired sample statistics was done with $95 \%$ confidence interval.

Group I BCVA: the mean Pre-Op visual acuity in terms of numbers was 34.80. The standard deviation was 7.01 with standard error of mean 1.811. The mean Post-Op mean was 49.13 with standard deviation 5.817 and standard error mean 1.502. The pre and Post op were analysed with paired samples test. The mean change in VA was 14.394 with standard deviation 7.40 and standard error mean 1.909.The P value was $<0.0001$ suggesting that the Avastin improves the visual acuity which is statistically significant.

Group I CMT: The mean Pre-Op central macular thickness was 578.27 microns with standard deviation 115.359 and standard error mean 29.786. The mean post-Op CMT was 204.00 microns with standard deviation 13.570 with standard error mean 3.504. The change in central macular thickness was 374.267 microns with standard deviation of 107.741 and $P$ value $<0.0001$ which suggests that Avastin reduces the central macular thickness to a statistical significant level.

Group II BCVA: The mean Pre-Op BCVA was 30.07 with standard deviation of 9.377 and standard error mean of 2.421. The Mean Post-Op BCVA was 47.73 with standard deviation of 11.585 and standard error mean of 2.991. The change in BCVA was 17.667 with standard deviation of 13.600 and standard error mean of 3.511. The $P$ value was $<0.001$ which is highly significant. This suggests that the combination therapy of avastin + Triamcinolone brings an increase in visual acuity by one month.

Group II CMT: the mean Pre-Op CMT was 586.27 with standard deviation 144.943 and standard error mean 37.424. Post op mean was 209.40 with standard deviation 18.38 and standard error mean 4.746

The paired samples test analysis shows a mean change of 376.867 microns with standard deviation of 153.318. P value was $<0.001$ which is highly significant, suggesting that the combination therapy brings down the macular thickness significantly.

INTERGROUP ANALYSIS: was done using "Independent samples test" with Levene's test for equality of variances. With regards to BCVA the mean increase in BCVA in group I was 14.33 and in group II was 17.67 the $\mathrm{P}$ value was 0.411 suggesting that, there is no statistically significant difference between both groups.

With regards to CMT the mean decrease in group I was 374.27 and in group II was 376.87. Group II had slightly more effect in decreasing the CMT but with P value is 0.958 , it is not statistically significant. 


\section{ORIGINAL ARTICLE}

Chart 3: Intergroup analysis: Change in Mean BCVA

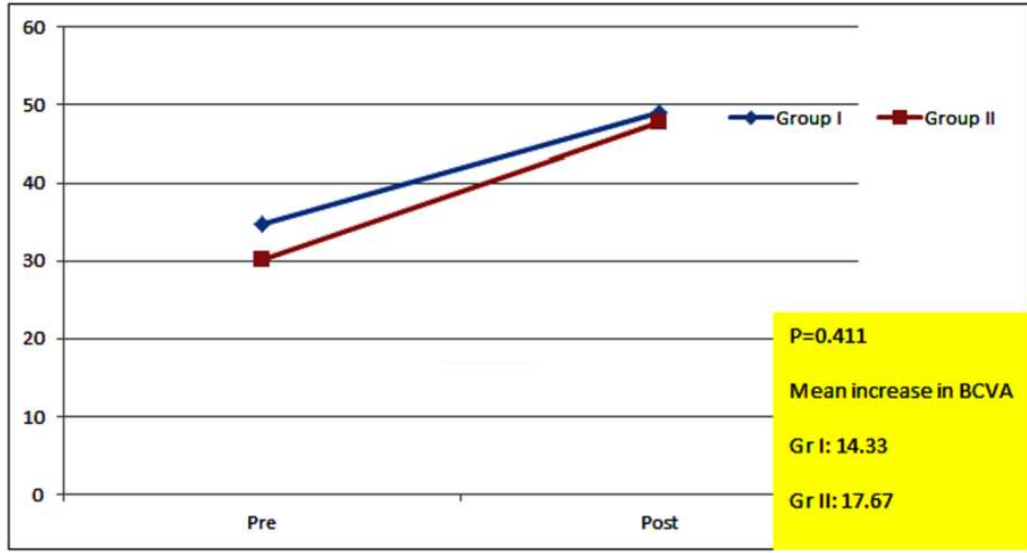

Chart 4: Intergroup analysis: Change in Mean CMT
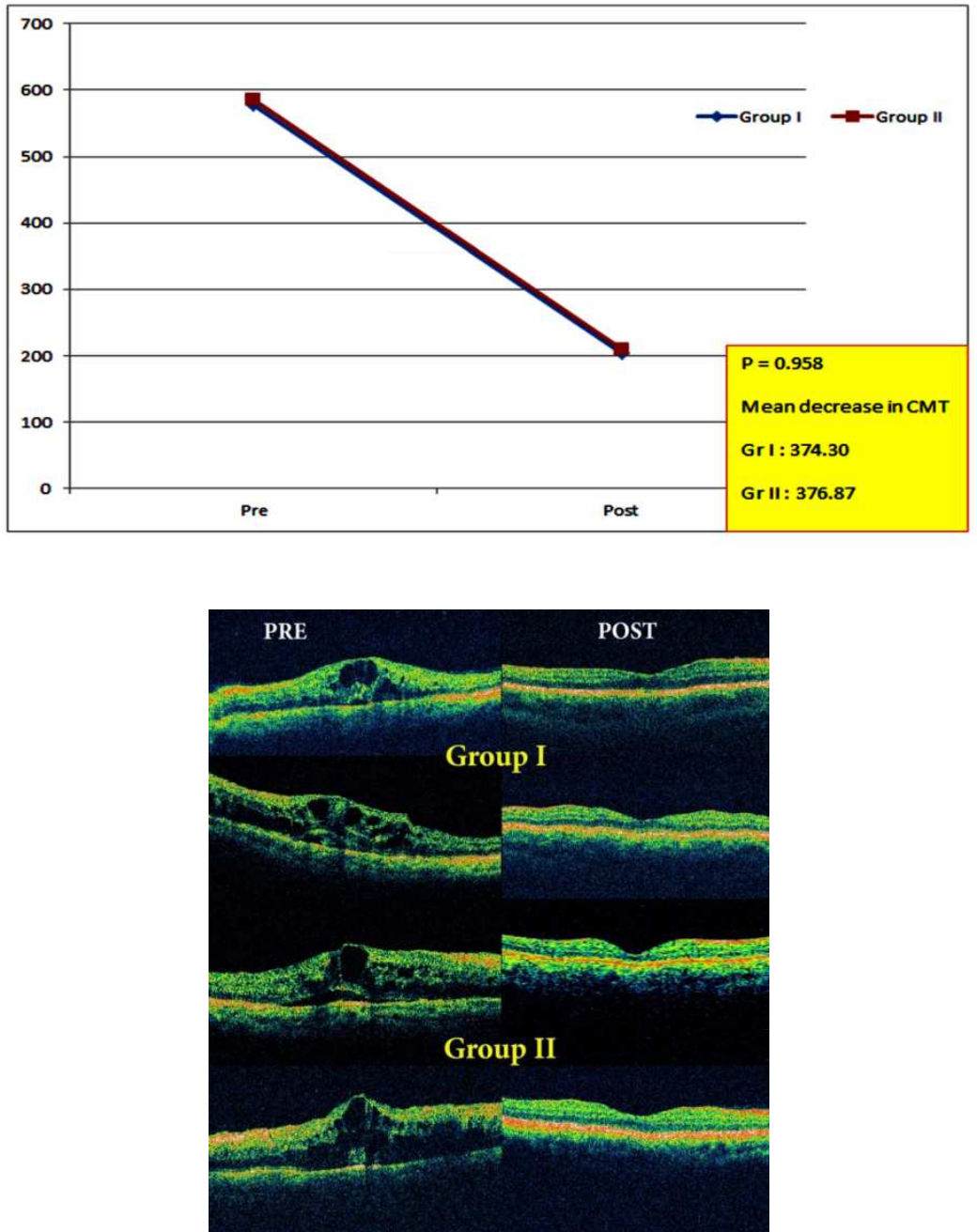

Photo 1. OCT examples: Pre Injection and Post injection. 
DISCUSSION: Macular edema is the most common cause for decreased vision in patients with CRVO. The macular edema is of vasogenic edema unlike in ischemic CRVO where the edema is cytotoxic macular edema.

Due to vein obstruction, blood stagnates in the venous system, thus increasing the pressure in capillary system leading to derangement in starling's forces. These changes also lead to secondary inflammation and result ultimately in breakdown of blood retinal barrier with, exudation of blood, fluid, and lipid into the retina, leading to the development of macular edema. Many cytokines are involved in this process which include VEGF, TGF, TNF, PDGF, IL-6,FGF etc. VEGF is the major vasopermeability factor that disrupts the blood-retina barrier in RVO by inducing fenestrations in capillaries and venules.

Average vitreal concentration of VEGF in CRVO is $8.6 \mathrm{ng} / \mathrm{ml}$ in CRVO, compared to 0.26 $\mathrm{ng} / \mathrm{ml}$ in normal eyes. ${ }^{28} \mathrm{~A}$ lower concentration of intraocular VEGF is required to increase vascular permeability than that required to induce neovascularization.

Untreated macular edema in CRVO typically persists for a long time. In one study, the median time to macular edema resolution was 23 months for nonischemic CRVO and 29 months for ischemic CRVO. ${ }^{29}$ Another study of five nonischemic CRVOs with macular edema reported a mean decrease in macular thickness of $173 \mu$ over 6 months. ${ }^{30}$ When macular edema persists, the risk of deterioration of visual acuity by greater than or equal to three Snellen lines is 3.22 times the risk in eyes in which macular edema resolves (95\% CI 1.86-5.57). ${ }^{29}$ Chronic macular edema and macular cysts in CRVO can result in a lamellar or full thickness macular hole. ${ }^{31}$

Early treatment of macular edema may be better for visual improvement before longstanding macular edema results in irreversible photoreceptor damage. 32

In CVOS, 728 eyes with CRVO were studied. ${ }^{33}$ Of these 728 Eyes, 155 (21\%) had macular edema reducing visual acuity to $20 / 50$ or worse (group M eyes, macular edema) The group M arm of the CVOS evaluated the treatment of macular edema in CRVO with grid laser photocoagulation in 155 eyes (77 treated eyes and 78 control eyes) over a 3-year followup period. All eyes had macular edema for a minimum of 3 months prior to enrollment. The CVOS found no significant difference in visual outcome between the treatment and observation groups at any follow-up point. Although there was a definite decrease in macular edema on fluorescein angiography in the treatment group when compared to the control group, this did not translate to a direct visual improvement. ${ }^{34}$

SCORE-CRVO Trial sponsored by National Eye Institute was designed (1) to determine whether intravitreal triamcinolone at 1-mg and 4-mg doses produces greater visual benefit, with an acceptable safety profile, than standard care and (2) to compare the efficacy and safety of 1-mg and 4-mg triamcinolone doses. The trial demonstrated that intravitreal injections of triamcinolone acetonide were superior to observation for vision loss associated with macular edema secondary to CRVO, and the $1 \mathrm{mg}$ dose of intravitreal triamcinolone had a safety profile superior to that of the 4 mg dose of intravitreal triamcinolone and similar to the observation group. The percentages of participants who achieved a gain in visual acuity letter score of 15 or more from baseline to month 12 were $27 \%, 26 \%$, and $7 \%$ in the $1 \mathrm{mg}, 4 \mathrm{mg}$, and observation groups, respectively. ${ }^{35}$

Since the first report in 2005, intravitreal bevacizumab is being commonly used for macular edema in CRVO with good results. ${ }^{21}$ 
In a prospective randomized interventional study, Ding X et al compared the efficacy of IVT versus IVB. 32 eyes of 31 patients were randomized to two groups of 16 each. BCVA improved and CMT decreased significantly in both groups at the end 1,3,6 and 9 months, but no statistical difference was noted. The mean number of treatment was $1.31 \pm 0.48$ in the IVT group, as compared with 2.38 \pm 1.04 in the IVB group. Significant IOP raise and Pre macular membranes were noted only in IVT group. 25

Ehrlich etal studied the effect of combined Intravitreal bevacizumab and triamcinolone in vein occlusions ( 8 BRVO, 8 CRVO) in a retrospective consecutive case series. Intravitreal bevacizumab (1.25 mg) combined with intravitreal triamcinolone (2 mg) was injected. They concluded that the combined treatment improves structural outcome, but the combination when compared with previously published results with IVB alone, did not offer any added advantage. ${ }^{26}$

There is no study till now, which compared the effect of intravitreal bevacizumab alone with combined intravitreal bevacizumab and triamcinolone. This is a prospective randomized consecutive interventional case series, comparing the both. Ischemic CRVO was excluded, as the ischemia and cytotoxic edema associated with ischemic CRVO may act as confounding factors. Also Avastin may further aggravate the ischemia.

After any intravitreal injection the IOP may raise due to increased intraocular volume. ${ }^{36,37}$ Therefore all patients receive oral acetazolamide for one day.

In group I the preop Visual acuity was $34.80 \pm 7.01$ (Mean \pm Standard deviation) which improved to $49.3 \pm 5.82$. There was increase in the BCVA by $14.33 \pm 7.40$. Visual acuity in group II increased from $30.07 \pm 9.38$ to $47.73 \pm 11.59$ by $17.67 \pm 13.60$.

The increase in BCVA seems to be more in group B clinically, but statistically, there is no difference between the two groups $(\mathrm{P}=0.411)$. This clinical superiority can be explained by the fact that combined therapy acts not just on VEGF but all other inflammatory mediators.

The Central Macular thickness in group I changed from $578.27 \pm 115.36$ to $204.00 \pm 13.57$ with a decrease of $374.27 \pm 107.74$. Central macular thickness in group II decreased from pre-op value of $586.27 \pm 144.94$ to post-op value of $209.40 \pm 18.38$. The change was $376.87 \pm 153.32$. With the $\mathrm{P}$ value 0.958 there is no difference between the two groups.

No serious complications were noted in either group. Transient raise in IOP was noted in group II which got corrected with topical medications. There are many previous studies which noted serious IOP raise, which required trabeculectomy in triamcinolone groups.

Previously in the same setup a study was done to compare the efficacy of Intravitreal Avastin versus combined Avastin with Triamcinolone for Diabetic macular edema. The results were almost similar. This shows that the VEGF is the main factor for edema in both cases. ${ }^{38}$

CONCLUSION: Both intravitreal Bevacizumab and combined intravitreal injection of bevacizumab and triamcinolone had beneficial effect in increasing the visual acuity and decreasing the central macular thickness in cases of recent onset macular edema due to central retinal vein occlusion.

Our results showed that both are equally efficacious. Multicentre randomized trials with longer followup are needed to evaluate the long term safety and efficacy of this combination treatment. Since both are equally effective and due to the known side effects of triamcinolone, Avastin alone can be used in the treatment of macular edema associated with central retinal vein occlusion. 


\section{REFERENCES}

1. Jonas JB, Nangia V, Khare A, Sinha A, Lambat S. Prevalence and associations of retinal vein occlusions: the Central India Eye and Medical Study.Retina 2013; 33(1):152-9.

2. Sohan Singh Hayreh.Retinal vein occlusion.IJO 1994;42(3):109-32.

3. Lee HB, Pulido JS, McCannel CA, Buettner H. Role of inflammation in retinal vein occlusion. Can J Ophthalmol. 2007;42(1):131-133.

4. Cohen T, Nahari D, Cerem LW, et al. Interleukin 6 induces the expression of vascular endothelial growth factor. J Biol Chem. 1996;271:736-41.

5. Behzadian MA, Wang XL, Al-Shabrawey M, Caldwell RB. Effects of hypoxia on glial cell expression of angiogenesis-regulating factors VEGF and TGF-beta. Glia. 1998;24:216-25

6. Schlingemann RO, van Hinsbergh VWM. Role of vascular permeability factor/vascular endothelial growth factor in eye disease. Br J Ophthalmol. 1997;81:501-12

7. McIntosh RL, Rogers SL, Lim L, Cheung N, Wang JJ, Mitchell P, Kowalski JW, Nguyen HP, Wong TY. Natural history of central retinal vein occlusion: an evidence -based systematic review. Ophthalmology. 2010;117:1113-23

8. Hayreh SS, Podhajsky PA, Zimmerman MB. Natural history of visual outcome in central retinal vein cclusion. Ophthalmology. 2011;118:119-33

9. Stefánsson E, Landers MB 3rd, Wolbarsht ML. Increased retinal oxygen supply following panretinal photocoagulation and vitrectomy and lensectomy. Trans Am Ophthalmol Soc. 1981;79:307-34

10. Arnarsson A, Stefánsson E. Laser treatment and the mechanism of edema reduction in branch retinal vein occlusion. Invest Ophthalmol Vis Sci. 2000;41:877-9.

11. The Central Vein Occlusion Study Group. Evaluation of grid pattern photocoagulation for macular edema in central vein occlusion: The Central Vein Occlusion Study Group M report. Ophthalmology. 1995; 102: 1425-33

12. Lu N, Wang NL, Li ZH, et al. Laser-induced chorioretinal venous anastomosis using combined lasers with different wavelengths. Eye. 2006; 19

13. Bavbek T, Yenice 0, Toygar 0. Problems with attempted chorioretinal venous anastomosis by laser for nonischemic CRVO and BRVO. Ophthalmologica. 2005; 219: 267-71

14. Nauck M, Roth M, Tamm M, et al. Induction of vascular endothelial growth factor by plateletactivating factor and platelet-derived growth factor is downregulated by corticosteroids. Am J Resp Cell Mol Biol. 1997; 16: 398-406.

15. Ip MS; Gottlieb JL; Kahana A; Scott IU; Altaweel MM; Blodi BA; Gangnon RE; Puliafito CA.Intravitreal triamcinolone for the treatment of macular edema associated with central retinal vein occlusion. Arch Ophthalmol. 2004; 122(8):1131-6 (ISSN: 0003-9950)

16. Cekiç O; Chang S; Tseng JJ; Barile GR; Weissman H; Del Priore LV; Schiff WM; Weiss M; Klancnik JM.Intravitreal triamcinolone treatment for macular edema associated with central retinal vein occlusion and hemiretinal vein occlusion. Retina. 2005; 25(7):846-50 (ISSN: 0275-004X)

17. Ozdek SC; Aydin B; Gürelik G; Bahçeci U; Hasanreisoğlu B.Effects of intravitreal triamcinolone injection on macular edema and visual prognosis in central retinal vein occlusion. Int Ophthalmol. 2005; 26(1-2):27-34 (ISSN: 0165-5701) 
18. Cheng $\mathrm{KC} ; \mathrm{Wu} \mathrm{WC}$; Lin CJ.Intravitreal triamcinolone acetonide for patients with macular oedema due to central retinal vein occlusion in Taiwan. Eye (Lond). 2009; 23(4):849-57 (ISSN: 1476-5454)

19. Konstantopoulos A, Williams CP, Newsom RS, Luff AJ. Ocular morbidity associated with intravitreal trimcinolone acetonide. Eye (Lond). 2007; 21(3): 317-320.)

20. Ip MS; Scott IU; VanVeldhuisen PC; Oden NL; Blodi BA; Fisher M; Singerman LJ;Tolentino M; Chan CK; Gonzalez VH.A randomized trial comparing the efficacy and safety of intravitreal triamcinolone with observation to treat vision loss associated with macular edema secondary to central retinal vein occlusion: the Standard Care vs Corticosteroid for Retinal Vein Occlusion (SCORE) study report 5. Arch Ophthalmol. 2009; 127(9):1101-14 (ISSN: 1538-3601);

21. Rosenfeld PJ, Fung AE, Puliafito CA. Optical coherence tomography findings after an intravitreal injection of bevacizumab (avastin) for macular edema from central vein occlusion. Ophthalmic Surg Lasers Imaging 2005;36:336-9

22. Iturralde D, Spaide RF, Meyerle CB, et al. Intravitreal bevacizumab (Avastin) treatment of macular edema in central retinal vein occlusion: a short-term study. Retina 2006;26:279-84.

23. Hsu J, Kaiser RS, Sivalingam A, et al. Intravitreal bevacizumab (avastin) in central vein occlusion. Retina 2007;27:1013-9

24. Tao Y; Hou J; Jiang YR; Li XX; Jonas JB.Intravitreal bevacizumab vs triamcinolone acetonide for macular oedema due to central retinal vein occlusion.Eye (Lond). 2010; 24(5):810-5 (ISSN: 1476-5454)

25. Ding X; Li J; Hu X; Yu S; Pan J; Tang S.Prospective study of intravitreal triamcinolone acetonide versus bevacizumab for macular edema secondary to central retinal vein occlusion. Retina. 2011; 31(5):838-45 (ISSN: 1539-2864)

26. Ehrlich R; Ciulla TA; Moss AM; Harris A.Combined treatment of intravitreal bevacizumab and intravitreal triamcinolone in patients with retinal vein occlusion: 6 months of follow-up. Graefes Arch Clin Exp Ophthalmol. 2010; 248(3):375-80 (ISSN: 1435-702X)

27. Rodrigues EB, Meyer CH, Grumann A Jr, Shiroma H, Aguni JS, Farah ME. Tunneled scleral incision to prevent vitreal reflux after intravitreal injection. Am J Ophthalmol 2007;143:10351037.

28. Ehlken C, Rennel ES, Michels D, et al. Levels of VEGF but not VEGF 165b are increased in the vitreous of patients with retinal vein occlusion. Am J Ophthalmol. 2011;152:298-303.

29. Hayreh SS, Podhajsky PA, Zimmerman MB. Natural history of visual outcome in central retinal vein occlusion. Ophthalmology. 2011;118:119-33.

30. Antcliff RJ, Mayer EJ, Williamson TH, Shilling JS. Early chorioretinal anastomosis in nonischaemic CRVO: a randomised trial. Br J Ophthalmol. 2005;89:780-1.

31. Shukla D, Rajendran A, Kim R. Macular hole formation and spontaneous closure after vitrectomy for central retinal vein occlusion. Graefes Arch Clin Exp Ophthalmol. 2006;244:1350-2.

32. Lin JM, Chiu YT, Hung PT, Tsai YY.Retina. 2007 Feb;27(2):180-9.Early treatment of severe cystoid macular edema in central retinal vein occlusion with posterior sub-tenon triamcinolone acetonide.

33. Central Vein Occlusion Study Group. Baseline and early natural history report. The Central Vein Occlusion Study. Arch Ophthalmol. 1993:111:1087-1095 


\section{ORIGINAL ARTICLE}

34. The Central Vein Occlusion Study Group. Evaluation of grid pattern photocoagulation for macular edema in central vein occlusion. The Central Vein Occlusion Study Group M Report.Ophthalmology. 1995;102(10):1425-1433

35. The SCORE Study Research Group. SCORE Study Report 5. A randomized trial comparing the efficacy and safety of intravitreal triamcinolone with observation to treat vision loss associated with macular edema secondary to central retinal vein occlusion. Arch Ophthalmol. 2009;127:1101-1114

36. Bakri SJ, Pulido JS, McCannel CA, et al. Immediate intraocular pressure changes following intravitreal injections of triamcinolone, pegaptanib, and bevacizumab. Eye 2009;23:181-185.

37. Kim JE, Mantravadi AV, Hur EY, et al. Short-term intraocular pressure changes immediately after intravitreal injections of anti-vascular endothelial growth factor agents. Am J Ophthalmol. 2008;146:930-934.

38. Murali Mohan Gurram. Comparison of Intravitreal Beva cizumab with Combined Beva cizumab and Triamcinolone for Untreated Diabetic Macular Edema. The Antiseptic. Vol 110 No.3 ISSN 0003-5998. P 142-7. 